\title{
The tourism industry in the Moroccan territory
}

\author{
Sara Sbai ${ }^{1}$
}

Received: 11/10/2012

1 IAE de Perpignan, Université de Perpignan Via Domitia - UPVD, 52 avenue Paul Alduy, 66860 Perpignan
Cedex, France; tel: +33 652642068 ; e-mail: srsbai@gmail.com, sara.sbai@univ-perp.fr

Supervisor: Dr Nicolas Peypoch and Dr. Jean Michel Hoerner

Institution awarding the Ph. D. Degree: University of Perpignan, France

Date of defence: $14^{\text {th }}$ September 2012

(C) 2013 International University College. All rights reserved

Citation: Sbai, S. (2013). The tourism industry in the Moroccan territory. Doctoral dissertation summary. European Journal of Tourism Research 6(1), 92-94.

\section{Goal and objectives of the dissertation \\ Goal:}

To identify the best practices and benchmarks in the Moroccan tourism industry.

\section{Objectives:}

$\checkmark$ To contribute to the tourism literature in both Moroccan and a wider international context.

$\checkmark$ To contribute to the development of the 'Destination Morocco'.

$\checkmark$ To analyse the tourism development strategies of Morocco by emphasizing on the different policy acts of the Moroccan government (Vision 2010 and Vision 2020) and their consequences to the evolution of tourism in the country.

$\checkmark$ To examine the strength and the factors of the tourism appeal of the country and the influence of Morocco as a tourism destination on the travellers' destination choice.

$\checkmark$ To provide with new proposals to increase the tourism investments in Morocco.

\section{Methodology:}

The first part is devoted to a general framework of tourism industry in three chapters. It's a description of the tourism system with a macro92 analysis on tourist movements and microanalysis on behavioural patterns that influence the travel decisions. We also conducted surveys over one hundred thirty tourists and potential tourists. We referred to French tourists who consider Morocco as a principle tourism destination because France is the primary tourism market for Morocco. Their preferences and requirements have been considered and linked with the literature review.

The second part shows that tourism has become a catalyst for economical projects and it is considered to be an important development tool for Morocco in both regional and national aspects. In this section, we examine further the strategy deployed by the country to integrate tourism into its territorial development policy. We look into the different territorial reorganisations which followed the "Vision 2010" and finally we do an overview of the implementation of all projects. This work was realised by the gathering and analyses of various data and documents provided by Ministry of tourism and Tourism observatory, which as a result details the various steps of their strategic work.

DOCTORAL DISSERTATION 
The third part offers an analysis of the competitiveness of Morocco as a tourist destination based on the productivity of selected hotels and travel agencies in the country. We worked with two application databases, which include 15 hotels and 15 travel agencies, representing all regions of Morocco.

Specifically we applied two quantitative methods. The first one is the Data Envelopment Analysis (Charnes et al., 1978) to measure the productivity changes between the two periods (2006-2008) through a Luenberger productivity index (based on the Malmquist productivity index). The Luenberger productivity index is divided into two parts: the first one describes the variation of technical efficiencies and the other - the technological advancements. Technical progress was further decomposed to test if it was natural or was influenced. The second quantitative method is the B-convexity and B-convexity inverse used to analyse the performance of 15 Moroccan travel agencies in 2006-2008.

\section{Theoretical conclusions:}

$\checkmark$ The thesis contributes to the academic knowledge identifying the implications of tourism in Morocco. It's a theoretical contribution in this field and, at the same time, it's an empirical thesis applied to Morocco, a destination that lacks academic attention.

$\checkmark$ Efficiency is partly endogenous to the enterprise, and therefore it is up to the management to improve it. But the rules of the game, including ethics (fair game), could be changed in its favour, and could allow some hotels to out-perform their less insightful rivals.

$\checkmark$ It can be stated that the productivity is driven by technological change for all hotels. The decomposition of technological change component underlines that the passage of time affects both the marginal rate of technical substitution between inputs and outputs. In other words, technological change is not neutral.

\section{Practical application of the dissertation}

Two applications are provided in two chapters which can provide policy recommendations to the private actors to enable them in order to make them effective. There are few empirical studies about tourism performance in Morocco in the academic literature. The methods used are robust and have the potential to contribute to a broader understanding of performance factor in tourism.

The general conclusion of the first study (Sbai \& Peypoch, 2011) is that the productivity was increased in all hotels which were analysed within the given period. Decomposition of the Luenberger productivity indicator clearly identifies the source of this growth. We observed that the high performances of the Moroccan hotels are almost always explained by the improvement of technical progress. Our findings encompass several combinations of efficiency and technological changes, signifying that there is room for adjustment in almost all hotels in order to achieve best practice procedures in hotel management.

The managerial aspects of the work are that the inefficient hotel's management must upgrade its procedures regarding operational activities in order to increase the efficiency. Managers should revise and change the hotels' strategies in a way which will lead them to reach the standards and classifications above the average. An example to approach would be including the adoption of pro-active strategies that capitalize in the growth of new market segments.

The second study was conducted to verify if the average performance was worsened or improved. The difference in the results obtained from both models: under the inverse B-convex model, 34 out of 45 observations were efficient, but we had only 25 out of 45 by using the BCC model. The number of the efficient travel agencies during the period analysed is 8 out of 15 with the inverse Bconvex model and only 4 out of 15 with the BCC model. These different results can be explained by the fact that Morocco has mass tourism, which generates increasing returns to scale, and we can naturally assume, for example, the existence of certain complements between operational costs excluding wages. These last two observations justify the second axis of explanation in our case study. From a 
managerial point of view, the inverse B-convex model enables the formulation of recommendations for the inefficient agencies in order to improve their technical efficiencies.

\section{Content of the dissertation}

\section{Abstract of chapter one:}

Chapter one presents the necessary and basic definitions of tourism grounded within the relevant literature. This first part primarily aims to understanding tourism and identify its key concepts.

\section{Abstract of chapter two:}

The second chapter is focuses on the tourism destinations. A number of elements of tourism destinations are introduced including development, planning, life cycle, tourism attraction and territory. A detailed presentation of recent theories with respect to attracting tourist is provided and a link to the notions of tourism territory is established.

\section{Abstract of chapter three:}

This chapter proposes a survey of different models of tourist behaviour. This chapter emphasises over the decision making about the destination choices and analyses the influences of the communication and promotion of the territory on this choice. In the broader sense of tourism demand, we consider that its result is finally a composition of individual behaviours. This chapter evokes a macroanalysis to explore the tourist movements, then a micro-analysis which explains the behaviour influence on travel decisions. Thus, by the correlation of these two analyses, it may be possible to comprehend the tourism market.

\section{Abstract of chapter four:}

Chapter four provides the reader with an account of the main tourism policy actions in Morocco taken in the recent years. The objectives of Vision 2010 (the planning and development of tourism in the country in order to reach 10 million tourists in 2010) and Vision 2020 (to be within the top 20 tourism destinations in the word) are clearly presented and detailed, especially with respect to the planning dimension. This chapter underlines the relation between the policy acts of the
Moroccan government and the evolution of tourism planning, with important consequences of better understanding the tourism supply and sustainable tourism concepts in Moroccan context.

\section{Abstract of chapter five:}

This chapter studies the various dimensions of tourism development, which provides a detailed discussion of the country's tourism product. This chapter examines more closely the new tourism development strategy launched by the kingdom to integrate the tourism into its territorial policy. It also serves as a link between Chapter four which focuses on policy and Chapter six.

\section{Abstract of chapter six: \\ Chapter six presents a discussion over the implications and limitations of tourism industry in Morocco, especially in respect with the cultural and geopolitical dimensions.}

\section{Abstract of chapter seven:}

It analyses the efficiency and productivity changes of a number of Moroccan hotels, as previously cited by using the Luenberger productivity indicator.

\section{Abstract of chapter eight:}

The last chapter studies specific empirical examinations of Moroccan travel agencies, already detailed above, measuring the technical efficiency.

\section{References:}

Charnes, A., Cooper, W.W., \& Rhodes, E. (1978). Measuring the efficiency of decision making units. European Journal of Operational Research, 2, 429-444.

Sbai, S., \& Peypoch, N. (2011). Productivity growth and biased technological change: The case of Moroccan hotels. International Journal of Hospitality Management, 30, 136140. 